\title{
Study on variations of peak strength of a sandstone during cyclic loading
}

\author{
A. Taheri $\cdot$ A. Royle $\cdot$ Z. Yang $\cdot$ Y. Zhao
}

Received: 7 September 2015/ Accepted: 5 November 2015/Published online: 16 November 2015

(C) Springer International Publishing Switzerland 2015

\begin{abstract}
An experimental investigation was carried out on Hawkesbury sandstone samples to study the peak strength variations during triaxial monotonic and cyclic compressive testing. Axial load, confining pressures and axial and lateral deformations were measured precisely from start of loading until postpeak state. Cyclic tests were carried out at different stress levels and unloading amplitudes. All the tests were performed at $4 \mathrm{MPa}$ confining pressure. A methodology to conduct cyclic loading testing was devised including the development of an innovative peak strength prediction method. The results confirmed that beginning of cyclic loading at higher stress will result in failure after fewer cycles. Moreover, it was found that if the specimen experience more cyclic loading the failure mode will be more brittle. The mechanical properties of the rock were altered by systematic cyclic loading; dependent upon the applied stress level during cyclic loading the rock may become weaker or stronger as a result of cyclic loading. It was identified that a critical maximum normalized deviator stress (i.e. deviator stress at the beginning of unloading normalized by rock peak strength) exists between 93.7 and $94.1 \%$ which defines the limit between peak strength hardening and weakening during cyclic loading. If the cyclic loading deviator stress is lower
\end{abstract}

A. Taheri $(\bowtie) \cdot$ A. Royle $\cdot$ Z. Yang $\cdot$ Y. Zhao School of Civil, Environmental and Mining Engineering, The University of Adelaide, Adelaide, Australia e-mail: abbas.taheri@adelaide.edu.au than this critical boundary, the peak strength increases up to $11 \%$. This increase in peak strength is directly proportional to the normalized deviator stress in unloading; the amount of increase in peak strength decreases with a decrease in cyclic loading deviator stress.

Keywords Hawkesbury sandstone $\cdot$ Cyclic loading · Peak strength

\section{Introduction}

Rock mass in underground and surface mines is exposed to systematic cyclic loading during drilling, mechanical excavation and truck haulage vibration or due to mine seismology. The mechanical properties of the rock are altered by cyclic loading and consequently rock may fail at stress levels lower than the monotonic failure stress. Such mechanisms could reduce the stability of the haul road and excavation boundaries and lead to failure which poses a significant hazard. In order to manage the risk, it is required to predict the effect of cyclic loading on mechanical properties of rocks.

Bieniawski (1967) defined the stages of brittle fracture of rock under triaxial compression and it was determined that cyclic testing should commence just prior to the onset of the unstable crack propagation stage to ensure fatigue failure of a specimen in a timely 
manner. This occurs between 70 and $85 \%$ of the peak strength where the stress-strain relation becomes nonlinear. Liu et al. (2012) and Xiao et al. (2010) defined damage as the creation and propagation of microcracks in a specimen which is considered to be continuous on a larger scale. Wasantha et al. (2015) looked at effect of joint geometry on fracturing behavior of rock joints. They observed a strong correlation between the fracture progression behaviours of the specimens with different failure mechanisms. Ge et al. (2003) examined the three stages of fatigue behaviour; volumetric compaction, volumetric dilation with strain hardening behaviour, and volumetric dilation with strain softening behaviour. It was found that the threshold for fatigue failure occurred at the transition point between volumetric compaction and volumetric dilation. Attewel and Farmer (1973) proposed that in cyclic loading failure occurs when the strain energy stored in the specimen exceeds a critical energy release level. They mentioned that just prior to this point, the rock have experienced a deformation state in which the incremental strains increase in proportion to the number of loading cycles. Bagde and Petros (2005) concluded that the dynamic energy sustained by the sample at a given testing condition could be treated as a rock characteristic indicating that this could influence the failure mechanism. Several studies performed by Haimson and Kim (1972), Eberhardt (1998) and Bagde and Petros (2005) confirmed that progressive micro-fracturing is the main cause of fatigue failure.

To date, a number of models have been established to predict damage of a rock as a result of compressive cyclic loading (Eberhardt et al. 1999; Chen et al. 2006; Xiao et al. 2010; Taheri and Tani 2013). However, the effect of various parameters during cyclic loading including unloading amplitude, stress level and confining pressure have not been studied together to predict peak strength during cyclic loading.

A significant problem that was noted with a majority of the studies was that the peak strength of the sample during monotonic loading was not accurately predicted, meaning that the effects of heterogeneity and variability among specimens were not taken into account (Eberhardt et al. 1999; Chen et al. 2006; Xiao et al. 2010; Koseki et al. 2003; Wang et al. 2013; Yang et al. 2015). In a study performed by Bastian et al. (2014) on Hawkesbury sandstone, the variability between the samples obtained from a single rock block was significant. Therefore, due to a lack of consistent and a representative amount of data it was not possible to develop a reliable model for predicting the damage and deformability attained by a rock under cyclic loading. This is the problem other ran into as well when performing cyclic loading on rock (e.g. Eberhardt et al. 1999; Zhengyu and Haihong 1990). Figure 1 shows the results of a study performed by Eberhardt et al. (1999) to quantify damage due to cyclic loading on rock. As can be seen in this figure, the unloading boundary is changed three times throughout the test, mainly because due to underestimation of rock monotonic peak strength, the selected unloading boundaries were not sufficient to fail the sample.

To solve the above mentioned problem, a method to predict rock peak strength, $q_{\mathrm{f}}$, without failing the specimen is required to allow results to be confidently attributed to cyclic loading processes, rather than estimating rock strength from previous tested specimens, assuming that all the samples are completely identical. A successful cyclic loading test requires the rock specimen to fail after a sufficient number of

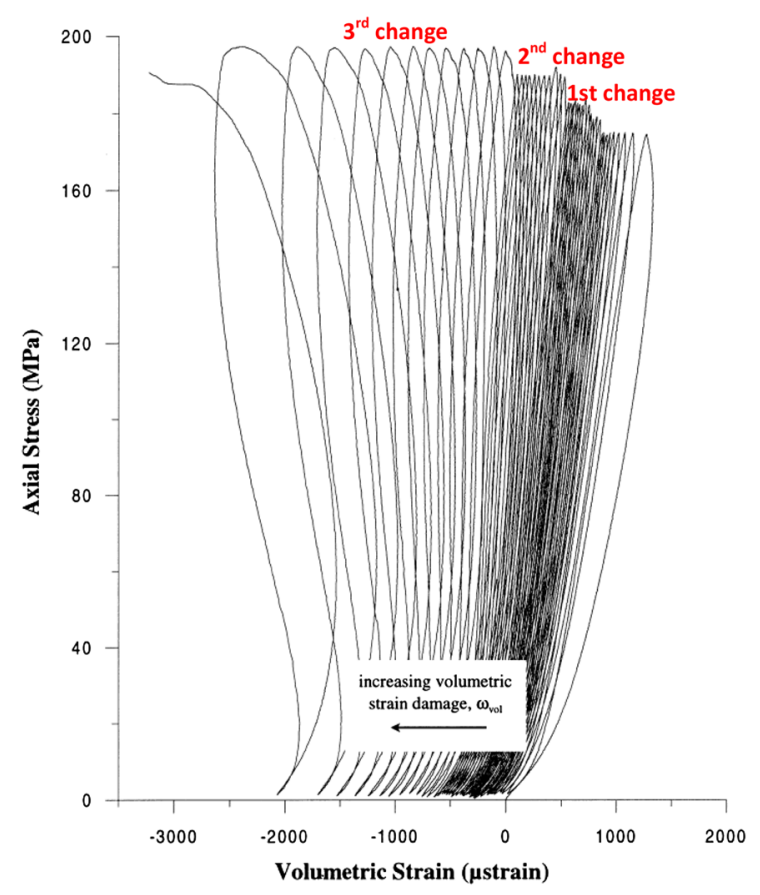

Fig. 1 Change of unloading stress boundary during cyclic loading test in axial stress-volumetric strain relations (adopted from Eberhardt et al. 1999) 
cycles without any change in unloading stress level and loading/unloading rate. During a cyclic loading test, when the predicted $q_{\mathrm{f}}$ value was much lower than the real peak strength, the designed cyclic loading axial stress level, $q_{\text {un }}$, would not be adequate to cause sufficient damage to break the rock. As the damage caused by every cycle, if any, was small, the number of cycles needed before the rock failed would be large hence the rock would not fail unless the $q_{\text {un }}$ or loading rate value was modified. Adjustments to $q_{\text {un }}$ or loading rate during a cyclic loading violate the principle of control variables during the test and render the results unreliable for damage model development. In addition, if the predicted $q_{\mathrm{f}}$ value was much higher than the real peak strength, the sample may experience a premature failure in the first cycle of loading. Hence, to prevent these situations, in this study the main challenge was to develop a method to accurately predict $q_{\mathrm{f}}$ of each rock sample and therefore obtain reliable test results. The results were then used to evaluate the effect of cyclic loading on peak and residual strength of sandstone.

\section{Methodology}

A total of 5 monotonic tests at loading rate of $0.05 \mathrm{~mm} / \mathrm{min}$ were undertaken to study the rock behaviour during monotonic loading and to develop a method to predict monotonic peak strength, $q_{\mathrm{f}}$ during cyclic loading tests. In addition 15 displacement controlled cyclic triaxial compression tests under confining pressure of $4 \mathrm{MPa}$ with loading/unloading rates of $5 / 10 \mathrm{~mm} / \mathrm{min}$ were completed on Hawkesbury sandstone specimens to study the effect of cyclic loading on peak strength. The two variables that were altered for each test were:

1. The maximum deviator stress applied to the specimen at each cycle, $q_{\text {un }}$.

2. Loading amplitude, $q_{\mathrm{b}}$, which will be set at 50,75 and $100 \%$ of $q_{\text {un }}$.

The Hawkesbury sandstone specimens were prepared according to International Society for Rock Mechanics (ISRM) standards. The specimens had dimensions of $100 \mathrm{~mm}$ in height and $42 \mathrm{~mm}$ in diameter. Two lateral and two axial strain gauges were fixed to the surface of the specimens in order to measure the true strain experienced by the specimen during loading.

Based on previous research, the Hawkesbury sandstone has an average strength around $40 \mathrm{MPa}$, therefore, a closed-loop servo-controlled testing machine with a loading capacity of $250 \mathrm{kN}$ was used for testing. The machine had a loading rate capability in the range of $0.001-10 \mathrm{~mm} / \mathrm{s}$ which was set at $5 \mathrm{~mm} / \mathrm{min}$ to ensure the confining pressure remained constant throughout the test. A high pressure Hoek cell and hydraulic pressure system were used to apply and control the confining pressure. The machine has a Linear Variable Differential Transducer (LVDT) to measure axial displacements.

To measure peak strength, $q_{\mathrm{f}}$, change of a sample subjected to cyclic loading, the peak strength under monotonic loading should be known prior to cyclic test. In the previous researches (e.g. Eberhardt et al. 1999; Gatelier et al. 2002; Bagde and Petros 2005; Yang et al. 2015) rock strength at monotonic loading was defined by conducting monotonic test(s) assuming that all the samples have similar strength. However, when testing Hawkesbury sandstone, as mentioned by Bastian et al. (2014), due to sample variability a wide range of monotonic strengths were measured at $4 \mathrm{MPa}$ confining pressure, ranging between 61 and $82 \mathrm{MPa}$. Hence the prediction of monotonic peak strength, $q_{\mathrm{f}}$, using the average monotonic tests results is not accurate for individual specimens. A model to predict the rock strength for each specimen before the cyclic loading is required.

In order to derive a method to predict the monotonic peak strength, $q_{\mathrm{f}}$, with potential indicator points, results of monotonic tests were further investigated. Figure 2 shows axial stress-strain relations obtained

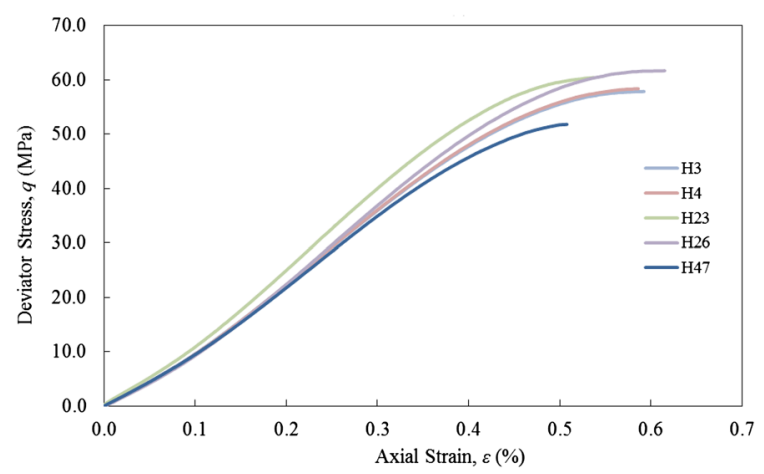

Fig. 2 Stress strain relations of monotonic triaxial tests 
by monotonic testing. As can be seen in this figure neither peak strength, nor stiffness of sample are identical. Peak strength of five specimens varies between 51.8 and $61.7 \mathrm{MPa}$ at $\sigma_{3}=4 \mathrm{MPa}$. It was intended to use stress-strain relations to obtain potential indicator point to predict monotonic peak strength, $q_{\mathrm{f}}$, of each sample during cyclic loading without damaging it. The indicator point should be easily monitored during testing and it must be able to predict $q_{\mathrm{f}}$ for Hawkesbury sandstone samples tested at $4 \mathrm{MPa}$ confining pressure, $\sigma_{3}$.

Analysing the results of monotonic tests, it was found that during monotonic loading the secant Young's modulus, $E_{\mathrm{sec}}$, evaluated by the external LVDT, keeps increasing until the axial stress come to a point closer to the failure point, after which the $E_{\mathrm{sec}}$ starts decreasing. The results showed that this point is a reliable indicative point to predict peak strength without damaging the sample. As schematically shown in Fig. 3, the deviator stress value at this indicator point, $q_{\text {id }}$, always provides a constant value for the ratio of $q_{\mathrm{id}} / q_{\mathrm{f}}$. As demonstrated in Table 1, the possibility of applying an offset to the secant Young's modulus was investigated in order to reduce the variability of $q_{\mathrm{id}} / q_{\mathrm{f}}$. The purpose of the offset also was to smooth out small scale fluctuations in the data as shown in Eq. 1. As shown schematically in Fig. 4 and then for a monotonic test in Fig. 5, as the offset

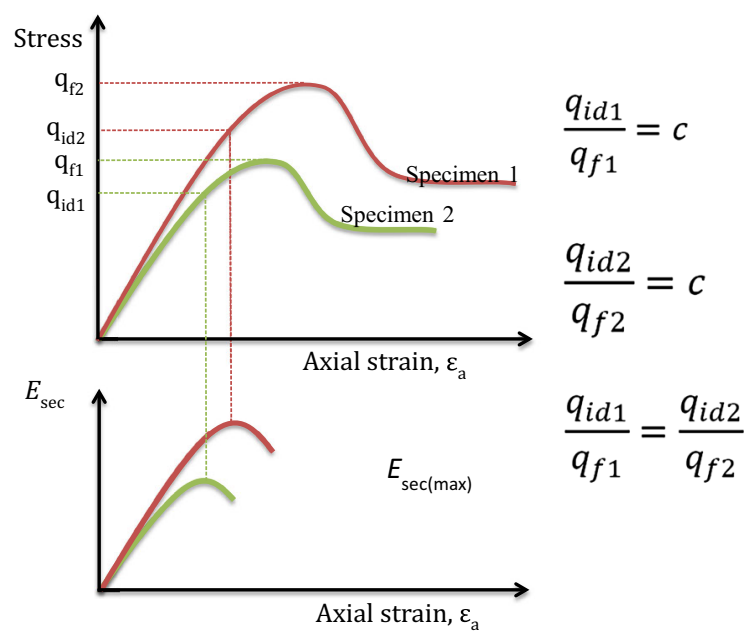

Fig. 3 Use of $E_{\mathrm{sec}}=$ max as an indicator point to predict peak strength increases, the deviator stress at $E_{\mathrm{sec}(\max )}$ with offset also increases. Figure 6 schematically shows Secant Young's modulus, $E_{\mathrm{sec}}$, values calculated from axial stress-strain results, by applying an offset. As shown in this figure after the indicator point, $q_{\text {id }}$, material shows large plastic deformation, stiffness reduces significantly and therefore, $E_{\mathrm{sec}}$ starts decreasing.

Table 1 shows that at $0.4 \%$ or higher value of offset, the ratio of $q_{\text {id }} / q_{\mathrm{f}}$ is always constant for sandstone samples having different peak strength and stiffness values. The maximum $E_{\mathrm{sec}}$ with $0.5 \%$ offset is the most accurate indicator for $q_{\mathrm{f}}$ prediction, however, in order to achieve a trade-off between accuracy and potential damage to the specimen, $0.4 \%$ offset was employed in this study using Eq. 2. The results obtained during cyclic loading didn't show any noticeable damage on sample due to pre-monotonic loading.

$E_{\text {sec }}$ with offset $=\frac{\text { Deviator } \text { stress }}{\text { strain }+ \text { offset }}$

$q_{f \text { Prediction }}=\frac{q_{i d}}{96 \%}$

After defining the indicator point, a methodology was designed such that a pre-monotonic load was applied to every sample prior to the commencement of cyclic loading. As the specimen must be intact when cyclic loading commences, the pre-monotonic load will be removed when $E_{\mathrm{sec}}$ peaks with $0.4 \%$ offset and rock peak strength predicted using Eq. 2. With post-test analysing the results after completing the cyclic loading test, the accurate peak strength can be estimated by knowing the exact axial stress where secant Young's modulus is the maximum value $\left(E_{\mathrm{sec}}=\max \right)$.

Figure 7 shows the proposed cyclic loading test procedure that was used in this study. Pre-monotonic loading was applied to every rock specimen until the indicator point was reached. The $q_{\mathrm{f}}$ value for each individual rock sample was then calculated based on the stress at indicator point, $q_{\text {id }}$. The $q_{\text {id }}$ was different for every sample however the ratio of $q_{\mathrm{id}} / q_{\mathrm{f}}$ was the same for all samples. As $q_{\mathrm{un}}$ is always smaller than $q_{\mathrm{f}}$, premature failure was avoided. The $\mathrm{X}$ value given in $q_{\mathrm{un}}=X \% \times q_{\mathrm{f}}$ was also implemented confidently. Therefore the likelihood of a time consuming test due to an insufficient $q_{u n}$ value was also reduced and large 
Table 1 Monotonic test results use to develop an indicator point to predict monotonic peak strength using stress-strain relations in cyclic loading tests

\begin{tabular}{llllllll}
\hline Specimen & $\begin{array}{l}\text { Monotonic peak } \\
\text { strength, } \mathrm{q}_{\mathrm{f}}(\mathrm{MPa})\end{array}$ & $\begin{array}{l}\mathrm{q}_{\mathrm{in}} * / \mathrm{q}_{\mathrm{f}} \text { at } \\
0 \% \text { offset }\end{array}$ & $\begin{array}{l}\mathrm{q}_{\mathrm{in}} / \mathrm{q}_{\mathrm{f}} \text { at } \\
0.1 \% \text { offset }\end{array}$ & $\begin{array}{l}\mathrm{q}_{\mathrm{in}} / \mathrm{q}_{\mathrm{f}} \text { at } \\
0.2 \% \text { offset }\end{array}$ & $\begin{array}{l}\mathrm{q}_{\mathrm{in}} / \mathrm{q}_{\mathrm{f}} \text { at } \\
0.3 \% \text { offset }\end{array}$ & $\begin{array}{l}\mathrm{q}_{\mathrm{in}} / \mathrm{q}_{\mathrm{f}} \text { at } \\
0.4 \% \text { offset }\end{array}$ & $\begin{array}{l}\mathrm{q}_{\mathrm{in}} / \mathrm{q}_{\mathrm{f}} \text { at } \\
0.5 \% \text { offset }\end{array}$ \\
\hline $\mathrm{H} 3$ & 57.884 & 0.81 & 0.88 & 0.91 & 0.93 & 0.95 & 0.97 \\
$\mathrm{H} 4$ & 58.398 & 0.81 & 0.87 & 0.89 & 0.92 & 0.95 & 0.97 \\
$\mathrm{H} 23$ & 60.457 & 0.84 & 0.91 & 0.93 & 0.97 & 0.97 & 0.98 \\
$\mathrm{H} 26$ & 61.713 & 0.85 & 0.91 & 0.94 & 0.95 & 0.96 & 0.97 \\
$\mathrm{H} 47$ & 51.830 & 0.88 & 0.91 & 0.95 & 0.97 & 0.97 & 0.98 \\
& Average: & 0.84 & 0.90 & 0.92 & 0.95 & 0.96 & 0.97 \\
\hline
\end{tabular}

* $\mathrm{q}_{\mathrm{in}}$ is equal to the deviator stress where secant Young's modulus peaks $\left(E_{\mathrm{sec}}=\max \right)$

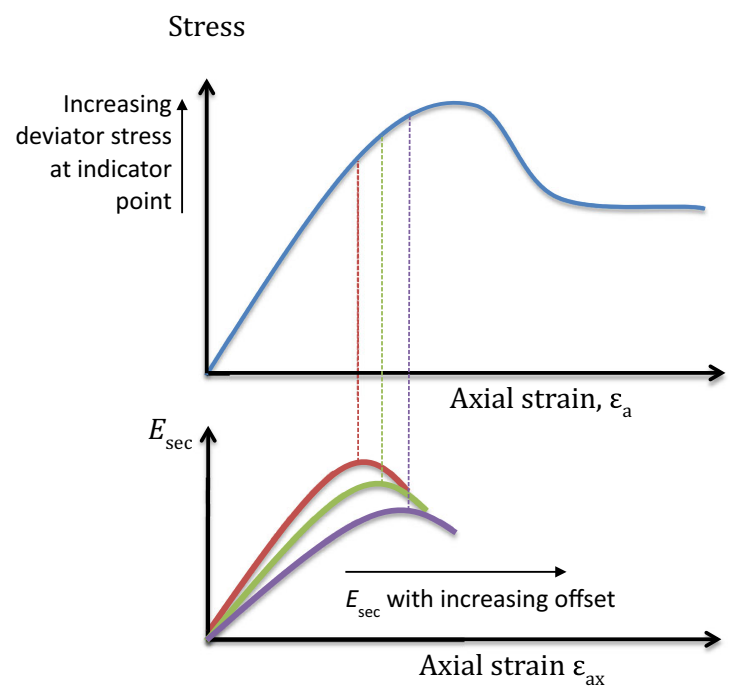

Fig. 4 Effect of increasing the offset applied to $E_{\mathrm{sec}}$ calculations on $q_{\text {id }}$

cycle numbers could be attributed to rock properties rather than inaccurate testing conditions. If the rock specimen did not fail after a large number of cycles, a monotonic load was applied until failure in order to examine the effect of long cyclic loading on the $q_{f}$ value.

\section{Analysis of results}

Figure 8 shows the deviator stress versus axial strain graph for a specimen failed as a result of cyclic loading. For Test HS33, cyclic loading was initiated at
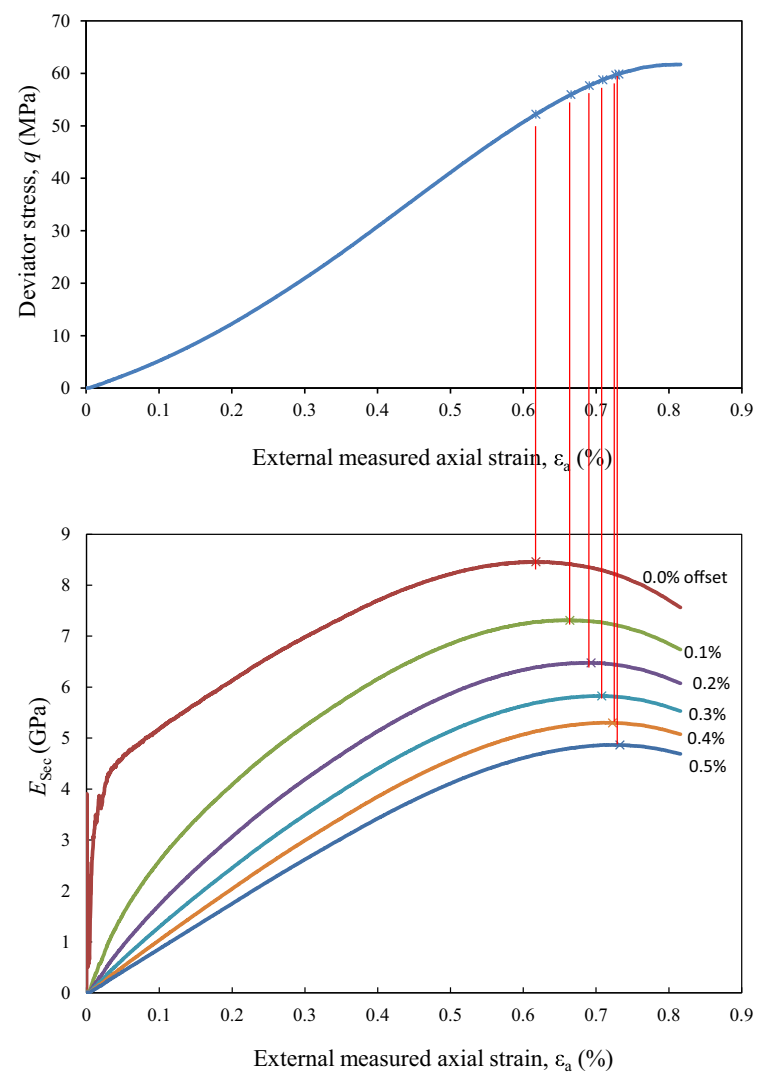

Fig. 5 Deviator stress calculated in a monotonic triaxial test (Test H26) when $E_{\mathrm{sec}}=\max$ with different offsets

$65 \mathrm{MPa}$ and requiring 68 cycles until failure. The stress-strain results in this figure are similar to those obtained by Xiao et al. (2009). The hysteretic loops are developed according to law of loose-dense-loose. Figure 9 shows the relations for Test HS43 which did 


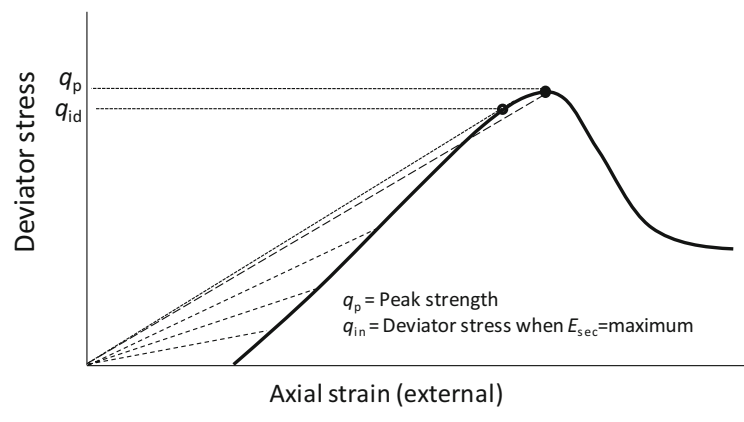

Fig. 6 Secant Young's modulus variations during axial loading

not fail during cyclic loading. In this test after 2255 loading/unloading a post-monotonic loading was applied to fail the specimen. As can be seen in this figure, the sample does not experience much axial plastic deformation after a large number of cycles and comparing with Fig. 8, the amount of permanent lateral and volumetric strain in the specimen during cyclic loading is very small. As discussed by Singh (1989), if the applied stress level in cyclic loading is considerably lower than the monotonic peak strength, rock won't fail during cyclic loading and it can even become stronger. The amount of permanent deformation during cyclic loading in peak or valley is usually considered as the amount of damage that the sample is experienced (e.g. Eberhardt et al. 1999). It will be shown in Sect. 5 that the sample for Test HS43 shows an increase in peak strength during a monotonic loading after a cyclic loading. Obviously this sample wasn't damaged during cyclic loading and therefore, the amount of permanent strain measured in this test during cyclic loading is very low.

It can be obtained that the deviator stress at failure for the specimen that did not fail after cyclic test is much higher than the upper limit of cyclic loading. An accurate post-test analysis was competed after the test by using the precise maximum $E_{\mathrm{sec}}$ obtained from the data file. Table 2 shows the results of cyclic loading tests carried out in this study.

\section{Rock damage}

The normalized deviator stresses for cyclic loading, $q_{\mathrm{un}} / q_{\mathrm{f}}$, and the normalized residual stresses, $q_{\mathrm{r}} / q_{\mathrm{f}}$, were investigated. In so doing, for specimens with unloading amplitude of $100 \%, q_{\mathrm{un}} / q_{\mathrm{f}}$ versus damage increment, $i$, at failure and $q_{\mathrm{r}} / q_{\mathrm{f}}$ versus axial strain at failure were plotted and shown in Fig. 10. To provide a consistent comparison, the results for the test at 75 and $50 \%$ of unloading amplitude are not included in this figure. Further tests should be conducted in the future to let the authors analyze the results of those tests as well. As shown in Fig. 10a, a higher normalized stress at unloading will result in failure after fewer cycles. In addition, Fig. 10b shows that if the specimen experience more axial strain before failure due to an increase of fatigue life, the failure is more brittle. In other words, during cyclic loading, the difference between peak strength and residual strength increases with an increase in axial strain at failure. This is mainly because by an increase in fatigue life, specimen is
Fig. 7 Proposed cyclic loading test procedure; (1) the indicator point was found during the first single loading; (2) the $q_{\mathrm{f}}$ value was predicted based on the relationship between the $q_{\text {id }}$ and $q_{\mathrm{f}}$; (3) $q_{\text {un }}$ was designed based on $q_{\mathrm{un}}=X \% \times q_{\mathrm{f}}$; and (4) $q_{\mathrm{b}}$ was defined based on $q_{\text {un }}$

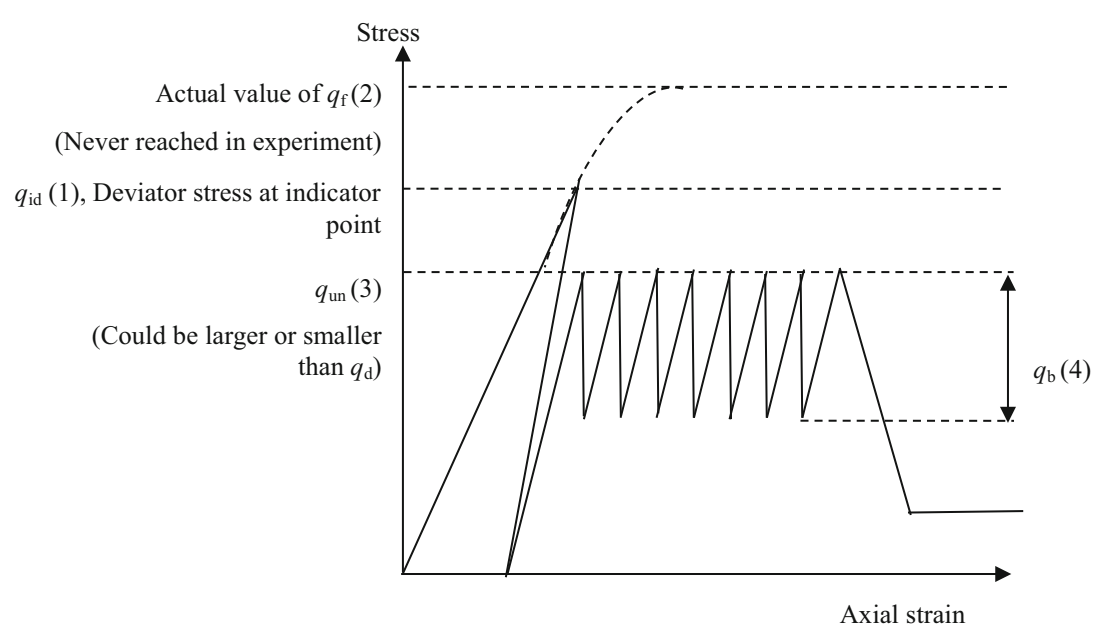



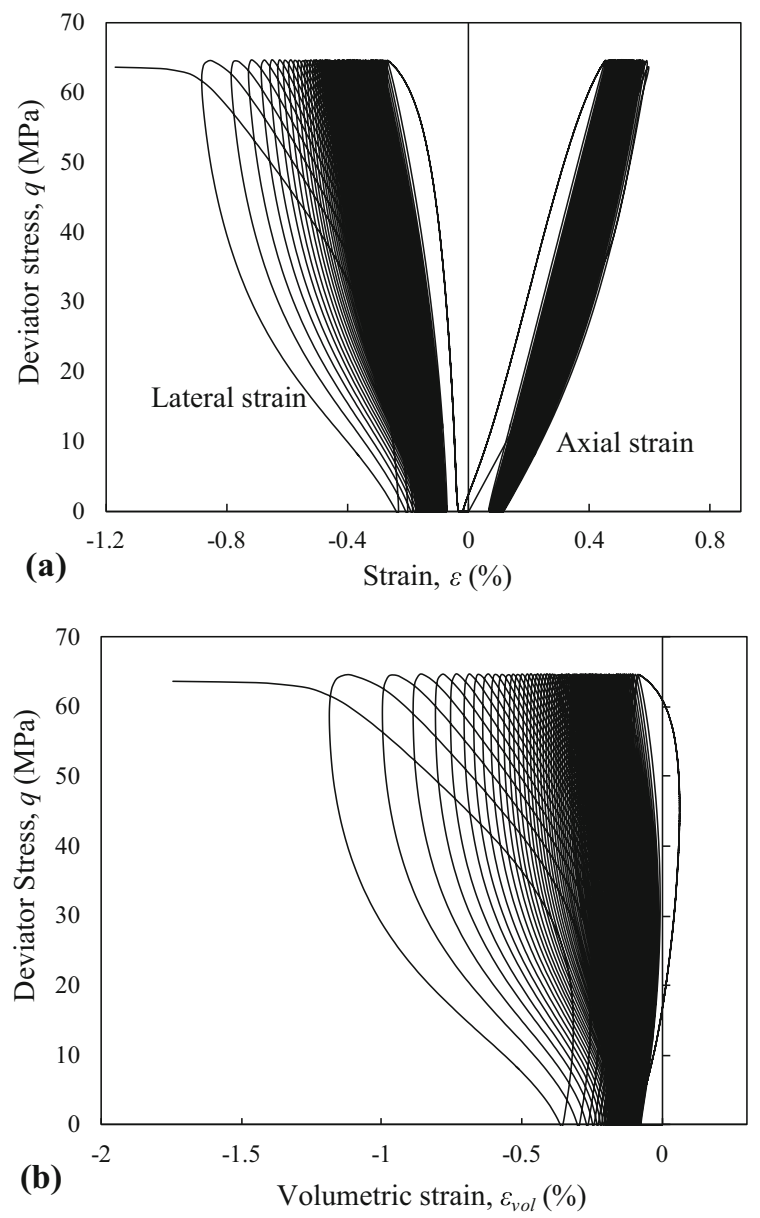

Fig. 8 An example of cyclic loading test results where the sample failed during cyclic loading (Test HS33); a deviator stress-axial and lateral strain relations; b deviator stressvolumetric strain relations

subjected to more damage until failure point. Therefore, failure behavior of a sample which experienced more damage before failure is more eruptive.

\section{Rock strength hardening}

In this section the behaviour of the rock specimens that did not fail as a result of the applied cyclic loading are discussed. Previous studies mostly support that the strength of rock decreases as a result of cyclic loading due to progressive damage of rock (Bieniawski 1967; Eberhardt et al. 1999; Chen et al. 2006; Xiao et al. 2010; Koseki et al. 2003; Wang et al. 2013). According to Ray et al. (1998), the percentage decrease in
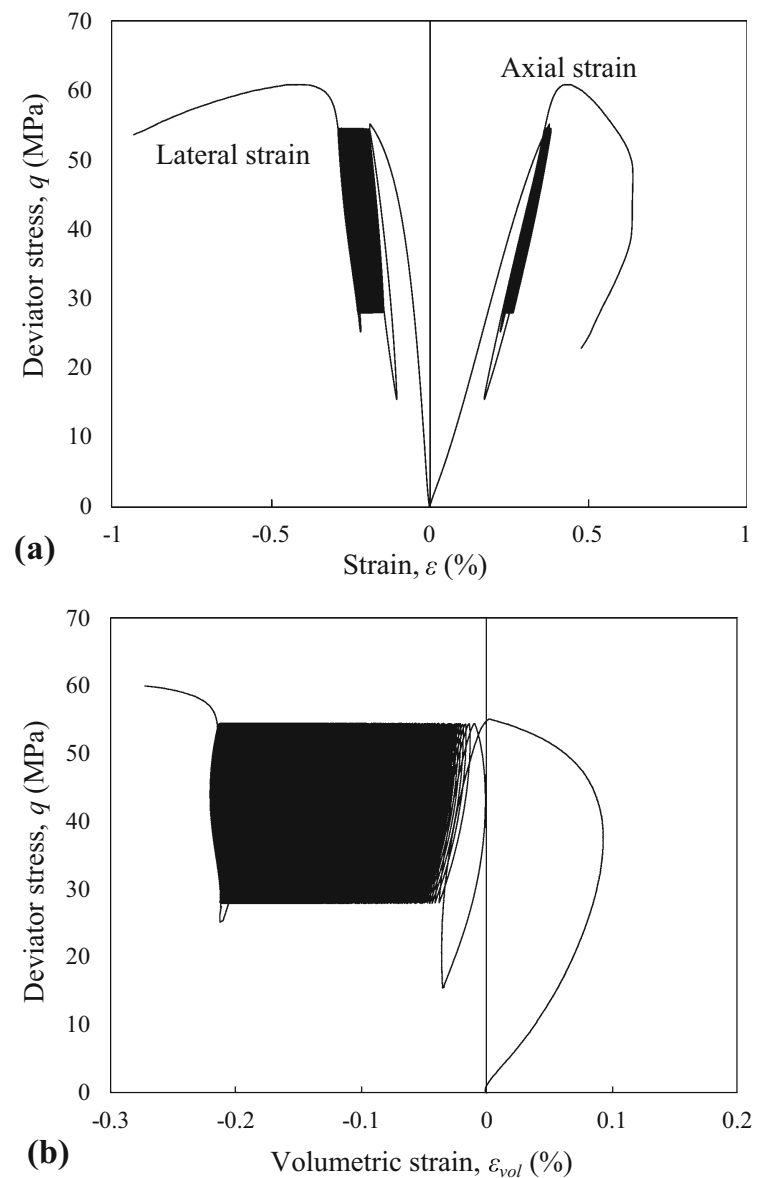

Fig. 9 An example of cyclic loading test results where the sample didn't fail during cyclic loading (Test HS43); a deviator stress-axial and lateral strain relations; b deviator stressvolumetric strain relations

uniaxial compressive strength increases with the number of cycles applied. Along with this, Singh (1989) discusses, however, that in some cases the applied stress level in cyclic loading does not cause rock failure during a very large number of cycles. Instead, the rock can become "strain hardened" and in turn increases its uniaxial compressive strength. Burdine (1963) compared the static strength of Berea sandstone samples with and without 1000 pre-cyclic loading under the same confining pressure. The results revealed that the static failure values for the samples experienced pre-cyclic loading are relatively higher than fresh samples. Cyclic loading can have very significant rock strength hardening effect. An investigation carried out by Ma et al. (2013) showed that the strength of rock salt can increase up to $171 \%$ after a 
Table 2 Summary of test results including amount of rock strength increase

\begin{tabular}{llllll}
\hline $\begin{array}{l}\text { Test } \\
\text { no. }\end{array}$ & $\begin{array}{l}\text { Actual } \\
q_{\text {un }} / q_{\mathrm{f}}(\%)\end{array}$ & $\begin{array}{l}\text { Unloading } \\
\text { amplitude }(\%)\end{array}$ & $\begin{array}{l}\text { Number } \\
\text { of cycles }\end{array}$ & $\begin{array}{l}\text { Failed during } \\
\text { cyclic loading? }\end{array}$ & $\begin{array}{l}\text { \% of rock strength } \\
\text { increase }(\%)\end{array}$ \\
\hline HS33 & 99.2 & 100 & 68 & $\mathrm{Y}$ & - \\
HS41 & 98.8 & 100 & 99 & $\mathrm{Y}$ & - \\
HS34 & 97.1 & 100 & 193 & $\mathrm{Y}$ & - \\
HS39 & 97.0 & 75 & 648 & $\mathrm{Y}$ & - \\
HS45 & 96.5 & 50 & 836 & $\mathrm{Y}$ & - \\
HS37 & 96.4 & 100 & 230 & $\mathrm{Y}$ & - \\
HS42 & 94.1 & 75 & 1344 & $\mathrm{Y}$ & - \\
HS43 & 93.7 & 50 & 2255 & $\mathrm{~N}$ & 4.0 \\
HS36 & 92.7 & 100 & 1265 & $\mathrm{~N}$ & 7.2 \\
HS40 & 91.9 & 100 & 1365 & $\mathrm{~N}$ & 11 \\
HS35 & 86.6 & 100 & 3739 & $\mathrm{~N}$ & 9.1 \\
HS50 & 84.0 & 100 & 1300 & $\mathrm{~N}$ & 5.3 \\
HS47 & 81.5 & 100 & 1300 & $\mathrm{~N}$ & 6.1 \\
HS49 & 70.4 & 100 & 1300 & $\mathrm{~N}$ & 3.0 \\
HS48 & 61.3 & 100 & 1300 & $\mathrm{~N}$ & 0.07 \\
\hline
\end{tabular}

certain number of cyclic loading during triaxial compressive testing.

Of the 15 tests, seven of the specimens failed as a result of cyclic loading. The fatigue stress for those specimens was found to be smaller than the predicted $q_{\mathrm{f}}$, which indicates a progressive damage mechanism due to cyclic loading. Eight of the specimens, however, did not fail after a large number of cycles. Therefore a monotonic load was applied until failure and post-peak state. It was found that in all eight tests which did not fail due to cyclic loading, the deviator stress at failure was higher than the predicted $q_{\mathrm{f}}$ value (see Table 2). This indicates that the strength of the rock specimens increased as a result of cyclic loading. In other words, if the stress level at the beginning of cyclic loading is not high enough to generate a failure in sandstone due to progressive cyclic loading damage, the rock strength, as a result of cyclic loading for a long period of time, may be increased.

The percentage of rock hardening is summarised in Table 2 in descending order of the actual $q_{\mathrm{un}} / q_{\mathrm{f}}$ applied to the rock specimens. The seven tests with the highest normalised deviator stresses all failed as a result of cyclic loading with $94.1 \%$ the lowest $q_{\mathrm{un}} / q_{\mathrm{f}}$ resulting in failure (specimen HS42). In the remaining eight tests, the specimens did not fail as a result of cyclic loading. These specimens had a lower $q_{\mathrm{un}} / q_{\mathrm{f}}$ than those that failed. Based on these results it is hypothesised that there exists a value of $q_{\mathrm{un}} / q_{\mathrm{f}}$ which lies between 93.7 and $94.1 \%$ that indicates the critical boundary of rock strength hardening and weakening under cyclic loading. In addition, Table 2 shows that the rock peak strength can increase up to $11 \%$ as a result of pre-cyclic loading.

Figure 11 shows that an increase in fatigue strength is directly proportional to the normalised deviator stress, $q_{\mathrm{un}} / q_{\mathrm{f}}$ in unloading. Hence, after 1300 cycles of systematic cyclic loading with $100 \%$ unloading amplitude in Hawkesbury sandstone specimens, the relationship between the rock strength increase percentage and normalised deviator stress at the upper limit of cyclic loading is given by the following Equation:

$R=0.2916 \times \frac{q_{u n}}{q_{f}}-0.1769$

where $\mathrm{R}$ is the percentage of rock strength increase as a results of cyclic loading, $q_{\mathrm{un}}$ is the unloading amplitude and $q_{\mathrm{f}}$ is the initial peak strength of the rock. The application of Eq. 3 is limited by the fixed damage increment and unloading amplitude. Further study into the behaviour of different rock types under different unloading amplitudes, $q_{\mathrm{b}}$, is required to define a generalized equation. 

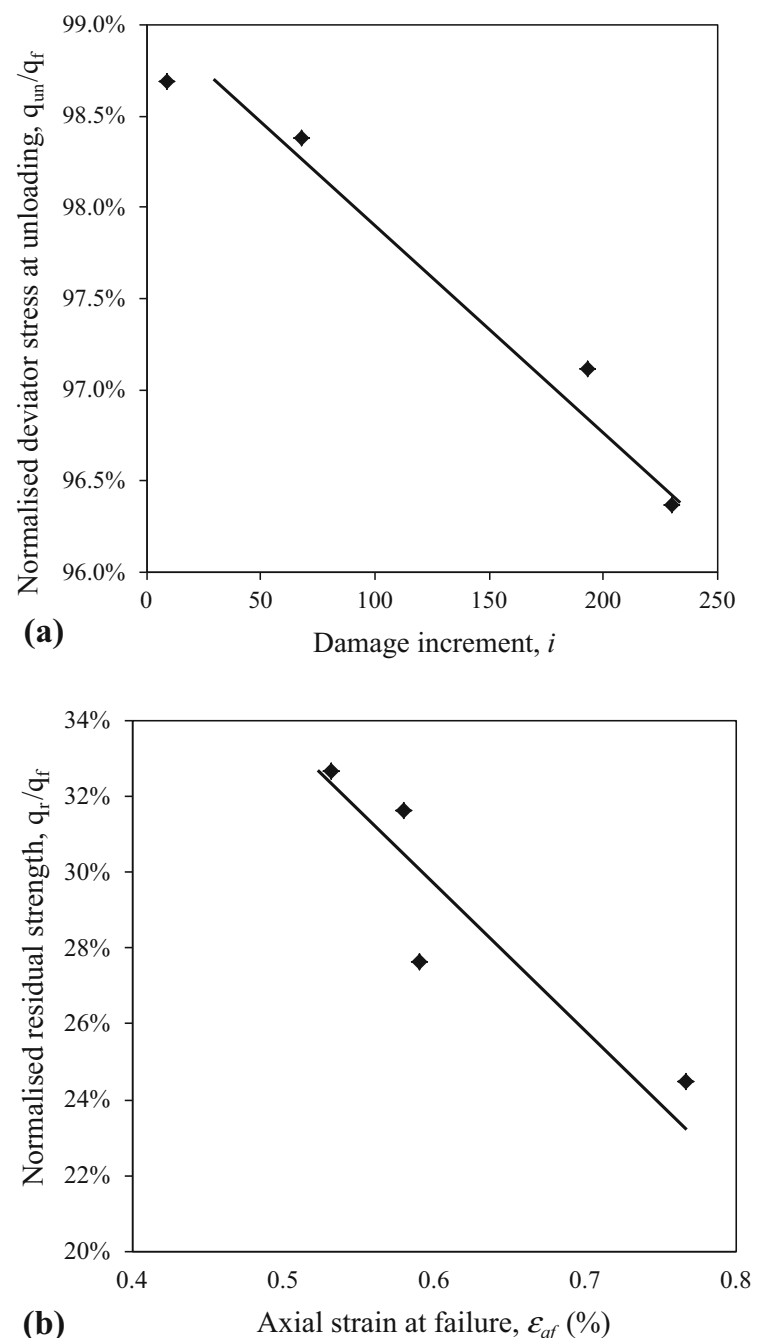

Fig. 10 a Normalized peak deviator stress at unloading versus damage increment at failure; b normalized residual deviator stress at unloading versus axial strain at failure

\section{Conclusions}

An experimental investigation was carried out using Hawkesbury sandstone to predict peak strength during triaxial cyclic compressive testing. A Methodology for successful cyclic loading testing was devised including the implementation of an innovative peak strength prediction method. The results give a strong indication that the peak strength prediction method was successful for all the tests undertaken in this study.

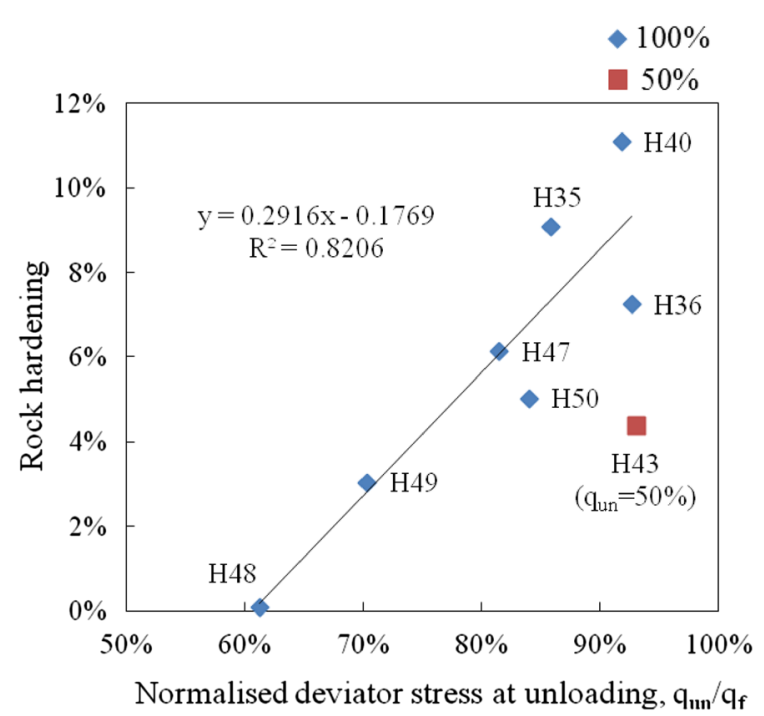

Fig. 11 Percentage increase in rock peak strength after cyclic loading versus normalised deviator stress at upper limit of cyclic loading

The normalized deviator stresses for cyclic loading, $q_{\mathrm{un}} / q_{\mathrm{f}}$, and the normalized residual stresses, $q_{\mathrm{r}} / q_{\mathrm{f}}$, were used to develop a preliminary damage model. The model confirmed that a higher normalized stress at unloading will result in failure after fewer cycles. Moreover, it was found that if the specimen experience more axial strain before the failure point, the failure will be more brittle, i.e. the difference between peak strength and residual strength increases.

This study confirmed that the peak strength of the sandstone is altered by cyclic loading. Dependent upon the stress level where the cyclic loading commences the rock may become weaker or stronger as a result of cyclic loading. It was found that, during cyclic loading fatigue failure happens if the stress level in cyclic loading is equal or higher that $94 \%$ of rock peak strength. If the cyclic loading deviator stress is lower than this critical boundary, the peak strength obtained by post-monotonic loading may increase up to $11 \%$. This increase in peak strength is directly proportional to the normalised deviator stress in unloading; the amount of increase in peak strength decreases with a decrease in cyclic loading deviator stress. 
Acknowledgments The authors wish to thank Mr. Simon Golding and Mr. Adam Ryntjes from the University of Adelaide for their help in conducting the tests.

\section{References}

Attewel PB, Farmer TW (1973) Fatigue behaviour of rock. Int J Rock Mech Min Sci 10:1-9

Bagde MN, Petros V (2005) Fatigue properties of intact sandstone samples subjected to dynamic uniaxial cyclical loading. Int J Rock Mech Min Sci 42:237-250

Bastian TJ, Connelly BJ, Lazo Olivares CS, Yfantidis N, Taheri A (2014) Progressive damage of Hawkesbury sandstone subjected to systematic cyclic loading. Res J Rev AusIMM 3:15-22

Bieniawski ZT (1967) Mechanism of brittle fracture of rock, Parts I, I \& III. Int J Rock Mech Min Sci 4:395-430

Burdine NT (1963) Rock failure under dynamic loading conditions. Soc Petrol Eng J 3:1-8

Chen ZH, Tham LG, Yeung MR, Xie H (2006) Confinement effects for damage and failure of brittle rocks. Int J Rock Mech Min Sci 43:1262-1269

Eberhardt E (1998) Brittle rock fracture and progressive damage in uniaxial compression, Ph.D. Thesis, College Of Studies and Research, Department of Geological Sciences, University Of Saskatchewan Saskatoo

Eberhardt E, Stead D, Stimpson B (1999) Quantifying progressive pre-peak brittle facture damage in rock during uniaxial compression. Int $\mathrm{J}$ Rock Mech Min Sci 36:361-380

Gatelier N, Pellet F, Loret B (2002) Mechanical damage of an anisotropic porous rock in cyclic triaxial tests. Int $\mathrm{J}$ Rock Mech Min Sci 39:335-354

Ge X, Jiang Y, Lu Y, Ren J (2003) Testing study on fatigue deformation law of rock under cyclic loading. Chin J Rock Mech Eng 22(10):1581-1585

Haimson BC, Kim CM (1972) Mechanical behaviour of rock under cyclic fatigue. Rock Mech NY Asce 13:845-863
Koseki J, Indou H, Hayano K (2003) Cyclic triaxial tests on residual deformation and small strain properties on soft rocks. Swets \& Zeitlinger B.V, Lisse

Liu E, Huang R, He S (2012) Effects of frequency on the dynamic properties of intact rock samples subjected to cyclic loading under confining pressure conditions. Rock Mech Rock Eng 45(1):89-102

Ma L, Liu X, Wang M, Xu H, Hua R, Fan P, Jiang S, Wang G, Yi Q (2013) Experimental investigation of the mechanical properties of rock salt under triaxial cyclic loading. Int $\mathbf{J}$ Rock Mech Min Sci 62:34-41

Ray SK, Sarkar M, Singh TN (1998) Effect of cyclic loading and strain rate on the mechanical behaviour of sandstone. Int $\mathbf{J}$ Rock Mech Min Sci 36:543-549

Singh SK (1989) Fatigue and strain hardening behaviour of Graywacke from the Flagstaff formation. Eng Geol 26:171-179

Taheri A, Tani K (2013) Developing a damage model to simulate multiple-step loading triaxial compression tests in rocks. Geotech Geol Eng 31:541-556

Wang Z, Li S, Qiao L, Zhao J (2013) Fatigue behaviour of granite subjected to cyclic loading under triaxial compression condition. Rock Mech Rock Eng 46:1603-1615

Wasantha PLP, Ranjith PG, Zhang QB, Xu T (2015) Do joint geometrical properties influence the fracturing behaviour of jointed rock? An investigation through joint orientation. Geomech Geophys Geoenerg Georesour 1:3-14

Xiao JQ, Ding DQ, Xu G, Jiang FL (2009) Inverted S-shaped model for nonlinear fatigue damage of rock. Int $\mathrm{J}$ Rock Mech Min Sci 46:643-648

Xiao JQ, Ding DX, Jiang FL, Xu G (2010) Fatigue damage variable and evolution of rock subjected to cyclic loading. Int J Rock Mech Min Sci 47:461-468

Yang S, Ranjith PG, Huang Y, Yin P, Jing H, Gui Y, Yu Q (2015) Experimental investigation on mechanical damage characteristics of sandstone under triaxial cyclic loading. Geophys J Int 201:662-682

Zhengyu T, Haihong M (1990) An experiment study and analysis of the behaviour of rock under cyclic loading. Int $\mathbf{J}$ Rock Mech Min Sci 27:51-56 